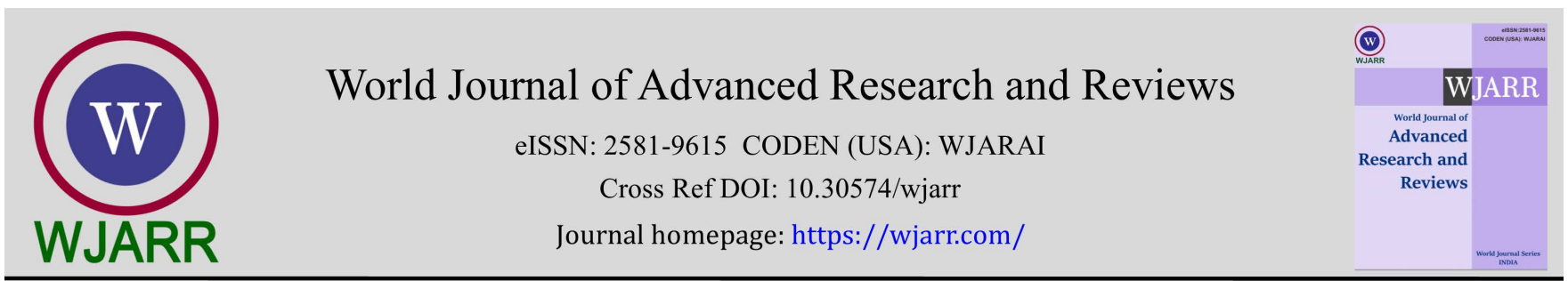

(RESEARCH ARTiClE)

Check for updates

\title{
Pattern of adverse events following immunization among recipients of first dose of ChAd0x1-S [recombinant] Covid-19 vaccine in a resource-limited country
} \author{
Chidimma Nwako ${ }^{4}$ and Charles Nwaora Nwako ${ }^{5}$ \\ ${ }^{1}$ Department of Paediatrics, Queen Elizabeth II Hospital, Maseru, Lesotho. \\ 2 Department of Internal Medicine, Federal Medical Centre, Owerri, Imo State, Nigeria. \\ ${ }^{3}$ Department of Paediatrics, Federal Medical Centre, Owerri, Imo State, Nigeria. \\ ${ }^{4}$ Primecare Hospital, Maseru, Lesotho. \\ ${ }^{5}$ Department of Pharmacy, Federal Medical Centre, Owerri, Imo State, Nigeria.
}

Azubuike Benjamin Nwako 1, *, Okechukwu Francis Nwako 2, Charles Emeka Nwolisa 3, Magaret-Lorritta

World Journal of Advanced Research and Reviews, 2021, 12(01), 006-012

Publication history: Received on 18 August 2021; revised on 28 September 2021; accepted on 30 September 2021

Article DOI: https://doi.org/10.30574/wjarr.2021.12.1.0470

\begin{abstract}
Background/Aim: Vaccines are said to be associated with side effects. The aim of the study was to show the pattern and distribution of adverse events following immunization observed with ChAdOx1-S [recombinant] Covid-19 vaccine after the first dose.

Methodology: The study design was cross-sectional descriptive study over four weeks. We included records of 6589 high risk recipients of the vaccine and 33 of them who reported adverse events following immunization. The study used secondary data from the covid-19 vaccination register and District Health Information system II.

Result: Out of 6589 individuals vaccinated with the first dose of ChAdOx1-S [recombinant] Covid-19 vaccine, 69.66\% were female, $69.49 \%$ were fifty-five years or less, $86.04 \%$ were health workers and $27.26 \%$ had comorbidity. Only $0.5 \%$ of those vaccinated reported adverse events following immunization out of which $0.41 \%$ was systemic, $0.06 \%$ local and $0.03 \%$ allergic reactions. The commonest systemic side effects were headache and dizziness while local adverse events had pain at injection site as the commonest side effect. Multiple swelling in the buttock and swelling of the face and lip were the only two cases of allergic reactions reported. Eighty-eight percent of those who reported side effects did so on the day of vaccination.
\end{abstract}

Conclusion The study reported less adverse events with the first dose of ChAdOx1-S [recombinant] Covid-19 vaccine than in other studies which included headache, dizziness and pain at the injection site. Most were reported in the first day of vaccination. There is need for encouraging vaccine recipients to report any adverse events following immunization.

Keywords: Adverse events following immunization; Side effect; Vaccine; Covid-19; Maseru; Lesotho

\section{Introduction}

Coronavirus sars-cov-2 infection, causing Covid-19, has negatively impacted the whole world causing a global pandemic. This has been associated with high morbidity and mortality. It was estimated that about $12.56 \%$ of the world's population were infected with Covid-19 since its detection in late 2019 [1,2]. The sub-Saharan countries have not been

\footnotetext{
${ }^{*}$ Corresponding author: Azubuike Benjamin Nwako

Department of Pediatrics, Queen Elizabeth II Hospital, Maseru, Lesotho.
}

Copyright (C) 2021 Author(s) retain the copyright of this article. This article is published under the terms of the Creative Commons Attribution Liscense 4.0. 
spared by this pandemic. This is worsened by the already burden of preventable diseases such as tuberculosis and human immunodeficiency virus (HIV) which has consumed the limited resources available in these region. The infection is transmitted from person to person through respiratory droplets and contact with contaminated surfaces $[3,4]$.

This devastating effect of Covid-19 needs a package of different approaches to combat and reverse its associated morbidity and mortality. Some of these measures include physical distancing, regular hand washing, use of hand sanitizers and regular cleaning of frequently used surfaces prone to contamination [5]. Those infected are treated symptomatically and there is currently no definitive treatment for covid-19.

Recently several vaccine types have been developed in an attempt to prevent or reduce the rate of infection, morbidity and mortality $[6,7,8]$. Some of these vaccines include Astrazeneca (ChAdOx1-S [recombinant]), Moderna and BioNTech vaccines [9]. One type of the vaccine is the mRNA vaccines such as Pizer-BioNTech and Moderna vaccines. The other type is the viral vector vaccines such as the Astrazeneca vaccine and the Johnson \& Johnson vaccine. They use adenovirus as their vector. The third group is the protein subunit vaccine. Majority of them are administered in the muscles of the upper arm and are given as two doses. However, Johnson \& Johnson vaccine is given as a single dose vaccine. All the vaccines act by stimulating the host immune system and thus producing antibodies, memory B-cells and T-lymphocytes [10].

These vaccines, like other existing vaccines, have been associated with various adverse events following immunization (AEFIs). They include pain at injection site, swelling at injection site, headache, dizziness and syncope [11,12]. Recently clots formation has been observed as a side effect associated with Astrazeneca vaccine [13].

Generally, AEFIs has been defined and classified by World Health Organization (WHO) into several types with corresponding causality assessment codes [14]. AEFI is defined as "any medical occurrence which follows immunization and which does not necessarily have a causal relationship with the usage of the vaccine. The adverse event may be any unfavourable or unintended sign, abnormal laboratory finding, symptom or disease." The first class of AEFI comprises of cases with adequate information for causality conclusion comprising codes A, B and C. Code A is consistent association to immunization. It comprises of Code A1 which is Vaccine product-related reaction, A2 being Vaccine quality defectrelated reaction, A3 being Immunization error-related reaction and A4 indicating Immunization anxiety-related reaction. Code B is indeterminate with Code B1 meaning that temporal relationship is consistent but there is insufficient definitive evidence for vaccine causing event. Code B2 indicates qualifying factors result in conflicting trends of consistency and inconsistency with causal association to immunization. Furthermore, Code $\mathrm{C}$ means inconsistent causal association to immunization (coincidental). The second class of AEFI comprises of cases with inadequate information for causality conclusion.

Astrazeneca vaccine was the first vaccine used in Lesotho. This vaccine was approved by the National Pharmaceutical Committee of the Ministry of Health Lesotho and is contained in the World Health Organization (WHO) Emergency Use Listing (EUL). Its use was started in March 2021 in Lesotho.

Lesotho is a landlocked country totally surrounded by South Africa. There is relatively easy flow of people between the two countries. Maseru is the capital of Lesotho and the biggest of the ten districts of the country and has border with South Africa.

The aim of this study was to show the AEFIs observed with Astrazeneca vaccine after the first vaccination of high risk group comprising mainly the health workers. This was further to describe the pattern of the adverse events following immunization. Finally, it was to describe the distribution of different types of AEFIs and their time of onset.

\section{Material and methods}

\subsection{Study site}

The study was carried out in Maseru district in Lesotho.

\subsection{Study design}

This was a cross-sectional descriptive observational study. The study was over a period of four weeks. 


\subsection{Study population}

The study included adults with age range from 18 to 89 years. These were those who were vaccinated only in Maseru District who did not present with symptoms and signs of covid-19 disease and were not diagnosed with Covid-19 in the last six months prior to vaccination. They were immunized and kept under observation for AEFIs for a period of 15 minutes before being allowed to leave the vaccination area. Those who did not report any AEFI at vaccination site were expected to report any AEFI at any time after the vaccination.

\subsection{Study instrument and data collection}

The study was done using the secondary data of all the at risk group especially the health workers who received the covid-19 vaccine who were recorded in the covid-19 vaccination register.

Data was obtained from the District Health Information System II (DHIS II) managed by the Maseru District Health Management Team (DHMT) office. Data was cleaned and stored in the computer of the principal investigator and was secured. High level of confidentiality was maintained.

\section{Results}

The vaccination took place from March 1, 2021 to March 31, 2021 and the vaccine recipients were aged between 18 and 89 years. The demographic findings of the recipients were shown in Table 1 . There were 6,589 recipients of the first dose of the covid-19 vaccine (ChAdOx1-S [recombinant]) of which female were 4590 (69.66\%) and male 1997 $(30.34 \%)$. The mean age of all the vaccine recipients were $41.23( \pm 15.4)$ years with $5479(83.15 \%)$ being 55 years or less. Majority of the recipients were health workers $(86.04 \%)$ while few were non-health workers $(13.96 \%)$ at high risk of contracting the infection. Of all the vaccine recipients, 1796 (27.26\%) reported comorbidity.

Table 1 Sociodemographic characteristics of all recipients of first dose of covid-19 vaccine (ChAdOx1-S [recombinant]) in Maseru District

\begin{tabular}{|c|c|c|}
\hline Recipients & $\begin{array}{c}\text { Number of vaccine } \\
\text { recipients } \\
\mathrm{N}=6589 \\
\end{array}$ & $\begin{array}{c}\text { Percentage } \\
(\%)\end{array}$ \\
\hline \multicolumn{3}{|l|}{ Sex } \\
\hline Male & 1999 & 30.34 \\
\hline Female & 4590 & 69.66 \\
\hline \multicolumn{3}{|l|}{ Age (years) } \\
\hline$\leq 55$ years & 4579 & 69.49 \\
\hline$>55$ years & 2010 & 30.51 \\
\hline Mean (SD) & $41.00(15.4)$ & \\
\hline Median (IQR) & $39(31-51)$ & \\
\hline Range & $20-89$ & \\
\hline \multicolumn{3}{|l|}{ Occupation } \\
\hline Doctors & 219 & 3.33 \\
\hline Nurses & 1416 & 21.49 \\
\hline Village Health workers & 1065 & 16.16 \\
\hline Other health workers & 2969 & 45.06 \\
\hline Non health workers & 920 & 13.96 \\
\hline \multicolumn{3}{|l|}{ Health status } \\
\hline No co-morbidities & 4686 & 71.12 \\
\hline Co-morbidities & 1796 & 27.26 \\
\hline Unknown & 107 & 1.62 \\
\hline
\end{tabular}


The demographic characteristics and types of side effects among recipients that reported adverse events were shown below in Table 2 . Of all the vaccine recipients, only $33(0.5 \%)$ of them reported any side-effect out of which $0.41 \%$ was systemic, $0.06 \%$ local and $0.03 \%$ allergic reactions. They were all acute in nature. Majority of them were females $(87.88 \%)$ and aged fifty-five years or less $(81.82 \%)$. The median age was $41.91( \pm 10)$ years. Among those who reported side-effects, $88 \%$ were systemic, $12.12 \%$ were local and $6.06 \%$ were due to allergic reactions. Headache and dizziness were commonest among the systemic side effects while pain at injection site was the commonest local side effects. There were only two cases of allergic reactions reported which were multiple swelling in the buttock and swelling of the face and lip.

Table 2 The demographic characteristics and types of adverse events following immunization among recipients of first dose of covid-19 vaccine (ChAd0x1-S [recombinant])

\begin{tabular}{|c|c|c|c|}
\hline & $\begin{array}{l}\text { Number with } \\
\text { side effect }\end{array}$ & $\begin{array}{l}\text { Percentage }(\%) \text { of } \\
\text { those who reported } \\
\text { side effect }(\mathrm{N}=33)\end{array}$ & $\begin{array}{l}\text { Percentage }(\%) \text { of all } \\
\text { vaccine recipients } \\
(\mathrm{N}=6589)\end{array}$ \\
\hline \multicolumn{4}{|l|}{ Sex } \\
\hline Male & 4 & 12.12 & 0.06 \\
\hline Female & 29 & 87.88 & 0.44 \\
\hline \multicolumn{4}{|l|}{ Age (years) } \\
\hline$\leq 55$ years & 27 & 81.82 & 0.41 \\
\hline$>55$ years & 6 & 18.19 & 0.09 \\
\hline Mean age (SD) & $41.91(17.5)$ & & \\
\hline Median(IQR) & $39(33-53)$ & & \\
\hline Range & $20-67$ & & \\
\hline \multicolumn{4}{|l|}{ Systemic side-effects } \\
\hline Any & 27 & 81.82 & 0.41 \\
\hline Headache & 14 & 42.42 & 0.21 \\
\hline Dizziness & 10 & 30.30 & 0.15 \\
\hline Tiredness & 4 & 12.12 & 0.06 \\
\hline Anxiety & 3 & 9.09 & 0.05 \\
\hline Diarrhoea & 2 & 6.06 & 0.03 \\
\hline Panic attack & 2 & 6.06 & 0.03 \\
\hline Sweating & 2 & 6.06 & 0.03 \\
\hline Palpitation & 1 & 3.30 & 0.015 \\
\hline Dry mouth & 1 & 3.03 & 0.015 \\
\hline Joint weakness & 1 & 3.03 & 0.015 \\
\hline Nausea & 1 & 3.03 & 0.015 \\
\hline Numbness of both & 1 & 3.30 & 0.015 \\
\hline legs & 1 & 3.03 & 0.015 \\
\hline \multicolumn{4}{|l|}{ Chills/shivers/rigors } \\
\hline Fever & 1 & 3.03 & 0.015 \\
\hline Shortness of breath & 1 & 3.03 & 0.015 \\
\hline Sore throat & 1 & 3.03 & 0.015 \\
\hline Cough & 1 & 3.03 & 0.015 \\
\hline cal side-effects & & & \\
\hline
\end{tabular}




\begin{tabular}{|l|c|c|c|}
\hline Any & 4 & 12.12 & 0.06 \\
\hline Pain & 3 & 09.09 & 0.05 \\
\hline Swelling & 1 & 03.03 & 0.015 \\
\hline Itch & 1 & 03.03 & 0.015 \\
\hline Allergic reactions & \multicolumn{3}{|l|}{} \\
\hline Any & 2 & 6.06 & 0.03 \\
\hline $\begin{array}{l}\text { Multiple swelling on } \\
\text { the buttocks }\end{array}$ & 1 & 03.03 & 0.015 \\
\hline $\begin{array}{l}\text { Swelling of the lips } \\
\text { and face }\end{array}$ & 1 & 03.03 & 0.015 \\
\hline Any AEFIs & 33 & & 0.50 \\
\hline
\end{tabular}

The reporting of side effects by day of onset was shown below in Fig 1. Most of the recipients (88\%) who had side effects reported on the day of vaccination. Three percent of the recipients each reported any side effect on days 2, 4, 12 and 13.

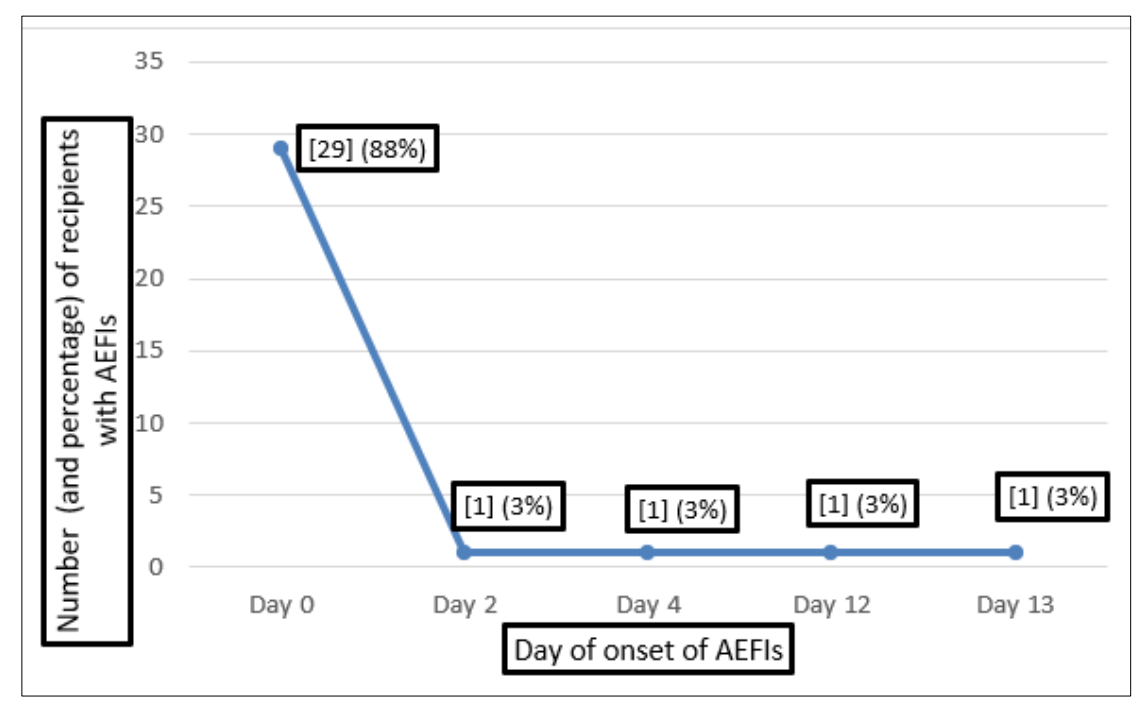

Figure 1 Vaccine recipients who reported adverse events following immunization with first dose of covid-19 vaccine (ChAdOx1-S [recombinant]) by day of onset

\section{Discussion}

The morbidity and mortality from Covid-19 became enormous globally. This led to rapid development of vaccines and their inclusion in the Emergency Use Listing (EUL) of the World Health Organization. Many developing countries including Lesotho, because of limited resources and paucity of expertise, relied on few results of researches from developed countries and on Emergency Use Listing of the World Health Organization. AstraZeneca vaccine was rapidly approved in Lesotho by the Pharmacoceutical committee under the watch of the Pharmacovigilance committee and the Surveillance unit of Expanded Programme on Immunization (EPI). This study population and those who reported AEFIs had a mean and median ages which were higher than the median age of Lesotho population which is 24.7 years [15]. This finding was similar to a study conducted in UK [16]. There were also more females in the study group which was similar to the finding of higher proportion of females in Lesotho Demographic and Health Survey 2014 [17]. There were more females who reported AEFIs to the vaccine. This could be due to more females in the study group. The percentage of the females among those with AEFIs were also more than in those who received the vaccine which rose from $69.66 \%$ to $87.88 \%$. This could be due to higher health seeking behaviour of females making them more likely to report side effects than males $[18,19]$. The mean age of those reporting AEFIs was similar to those who received the vaccine. There were more AEFIs reported by those aged 55 years or less. This was seen in a multi-Centre study done in Brazil, South Africa and the UK [20]. There was low level (0.5\%) of AEFIs reported among the recipients of the vaccine in this group than other studies [16,21]. This low level of AEFIs could likely be that the recipients were not given adequate information on the reporting of AEFIs. This possible effect of low level of knowledge about reporting AEFIs could result 
in low reporting of AEFIs as was observed in a study in Albania [22]. It could also possibly be due to less occurrence of AEFIs in the study group. This could also be affected by the reduced contact between recipients of vaccine and the vaccinators because of the physical distancing required, thus making them less likely to report. Further, it could be due to the absence of reporting device as was seen in the UK study [16].

Among the systemic adverse events, headache, dizziness and tiredness were the commonest side effects reported. This was similar to the finding in Saudi Arabia [21]. Pain at injection site was the commonest local adverse events in this study. This AEFI was also reported in other studies [16,21]. Multiple swelling of the buttock and swelling of the face and lip were the only allergic reactions reported in this group. However, only face and lip swelling was reported in the UK study without swelling of the buttocks [16]. Most (88\%) of the vaccine recipients reported their AEFIs within the first day of vaccination. Only $9 \%$ of the recipient reported any adverse event after the $4^{\text {th }}$ day up till the $13^{\text {th }}$ day of vaccination. The finding of early presentation has been observed in other studies [16,21]. There was no bleeding disorder or neurological sequel that was reported after the first dose of AstraZeneca vaccine in our study as was seen or suspected in other studies [23,24]. All the recipients with adverse events in this group recovered fully.

Some of the limitations included the fact that this was a cross-sectional study involving use of secondary data. The comorbidities were not captured in the vaccine line list where the AEFIs were recorded thus making it difficult to assess the distribution of AEFIs with comorbidity. The safety measures taken during the vaccination was also not made known to help in interpreting the AEFIs. The AEFIs were only obtained through self-reporting technique and this could introduce reporting bias. There were also no laboratory tests done for assessing the effect of the vaccine on the blood profile.

\section{Conclusion}

Adverse events following immunization were observed among recipients of the first dose of ChAdOx1-S [recombinant] vaccine in Maseru Lesotho. The study reported less AEFIs than other studies. The commonest side effects included headache, dizziness, tiredness and pain at the injection site. Most of the adverse events following immunization were reported in the first day of vaccination and all the recipients recovered fully. There is need for encouraging all Covid-19 vaccine recipients to report adverse events following immunization.

\section{Compliance with ethical standards}

\section{Acknowledgments}

Firstly, we acknowledge Keneuoe Sefuba Moketetsa and Mokuku for some technical support. Secondly, to Mr Mokone Mpeete and Mr Lebohang Rantsatsi for their support in analysis of the data. Finally, we acknowledge all the recipients of the first dose of ChAdOx1-S [recombinant] vaccine recipients.

\section{Disclosure of conflict of interest}

Authors have declared that no competing interests exist.

\section{Statement of ethical approval}

Ethical clearance was obtained from Ministry of Health Research and Ethics Committee Lesotho with reference number, REF: ID27-2021.

\section{Statement of informed consent}

Informed consent was obtained from all individual participants included in the study.

\section{References}

[1] Ayoub H, Mumtaz G, Seedat S, Makhoul M, Chemaitelly H, Abu-Raddad LJ. Estimates of global SARS-CoV-2 infection exposure, infection morbidity and infection mortality rates. 2021.

[2] Philips S, Grafton RQ, Kompas T. Robust estimates of the true (population) infection rate for COVID-19: a backcastingapproach. Royal Society Open Science. 2020; 7: 200909. 
[3] Chan J, Yuan S, KOk K. A familial cluster of pneumonia associated with the 2019 novel coronavirus indicating person-to-person transmission: a study of a family cluster. Lancet. 2020; 395(10223): P514-523.

[4] WHO. Modes of transmission of virus causing COVID-19: implications for IPC precaution recommendations. Scientific brief. 2020.

[5] Guner HR, Hasanoglu I, Aktas F. COVID-19: prevention and control measures in community. Turkish Journal of medical sciences. 2020; 50(3): 571-577.

[6] Thanh Le T, Andreadakis Z, Kumar A, Roman RG, Tollefsen S, Saville. Covid-19 development landscape. Nat Rev Drug Discov. 2020; 19(5): 305-306.

[7] Graham BS. Rapid COVID-19 vaccine development. Science. 2020; 368 (6494): 945-946.

[8] Jeyanathan M, Afkhami S, Smaill F, Miller MS, Lichty BD, Xing Z. Immunological considerations for COVID-19 vaccine strategies. Nature Reviews Immunology. 2020; 20: 615-632.

[9] Chung YH, Beiss V, Fiering SN, Steinmetz NF. COVID-19 vaccine frontrunners and their nanotechnology design. ACS nano. 2020; 14(10): 12522-12537.

[10] Speiser DE, Bachman MF. COVID-19: Mechanisms of vaccination and immunity. Vaccines. 2020; 8(3): 404.

[11] Knoll MD, Wonodi C. Oxford -AstraZeneca COVID-19 vaccine efficacy. The Lancet. 2021; 397(10269): P72-74.

[12] Thanh Le T, Cramer JP, Chen R, Mayhew S. Evolution of the Covid-19 vaccine development landscape. Nat Rev Drug Discov. 2020; 19(10): 667-8.

[13] Wise J. Covid-19: European countries suspend use of Oxford-AstraZeneca vaccine after reports of blood clots. BMJ. 2021; 372: n699.

[14] World Health Organization. Causality assessment of an adverse event following immunization (AEFI): user manual for the revised WHO classification. 2013.

[15] Lesotho Demographics Profile. Index Mundi. 2020. Accessed 17 August 2021.

[16] Menni C, Klaser K, May A, Polidori L, Capdevila J, Louca P, et al. Vaccine side-effects and SARS-CoV-2 infection after vaccination in users of the COVID Symptom Study app in the UK: a prospective observational study. Lancet Infect Dis. 2021; 21: 939-49.

[17] Lesotho Demographic and Health Survey. 2014. Accessed 17 August 2021.

[18] Lim MT, Lim YMF, Tong SF, Sivasampu S. Age, sex and primary care setting differences in patients' perception of community healthcare seeking behaviour towards health services PLoS One. 2019; 14: e0224260.

[19] Thompson AE, Anisimowicz Y, Miedema B, Hogg W, Wodchis WP, Aubrey-Bassler K. The influence of gender and other patient characteristics on health care-seeking behaviour: a QUALICOPC study. BMC Fam Pract. 2016; 17: 38.

[20] Voysey M, Clemens SAC, Madhi SA, Weckx LY, Folegatti PM, Aley PK, et al. Safety and efficacy of the ChAdOx1 nCoV-19 vaccine (AZD1222) against SARS-CoV-2: An interim analysis of four randomised controlled trials in Brazil, South Africa, and the UK. Lancet. 2021; 397: 99-111.

[21] Alhazmi A, Alamer E, Daws D, Hakami M, Darraj M, Abdelwahab S, et al. Evaluation of Side Effects Associated with COVID-19 Vaccines in Saudi Arabia. Vaccines. 2021; 9: 674.

[22] Mehmeti I, Nelaj E, Simaku A, Tomini E, Bino S. Knowledge, practice and approaches of health professionals to adverse events following immunization and their reporting in Albania. Heliyon. 2017; 3(6): 000331.

[23] Wise J. Covid-19: European countries suspend use of Oxford-AstraZeneca vaccine after reports of blood clots. BMJ. 2021; 372.

[24] Lu L, Xiong W, Mu J, Zhang Q, Zhang, Zou L. Neurological side effects of COVID-19 vaccines are rare. Acta Neurol Scand. 2021; 144: 111-112. 